\title{
Laser-Based Aid Systems for Berthing and Docking
}

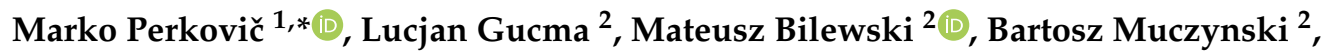 \\ Franc Dimc ${ }^{1}\left(\mathbb{D}\right.$, Blaž Luin $^{1}{ }^{\mathbb{D}}$, Peter Vidmar ${ }^{1}$, Vivien Lorenčič ${ }^{1}$ and Milan Batista ${ }^{1}$ \\ 1 Faculty of Maritime Studies and Transport, University of Ljubljana, 6320 Portorož, Slovenia; \\ franc.dimc@fpp.uni-lj.si (F.D.); blaz.luin@fpp.uni-lj.si (B.L.); peter.vidmar@fpp.uni-lj.si (P.V.); \\ vivien.lorencic@fpp.uni-lj.si (V.L.); milan.batista@fpp.uni-lj.si (M.B.) \\ 2 Faculty of navigation, Maritime University of Szczecin, 70-500 Szczecin, Poland; \\ l.gucma@am.szczecin.pl (L.G.); m.bilewski@am.szczecin.pl (M.B.); b.muczynski@am.szczecin.pl (B.M.) \\ * Correspondence: Marko.Perkovic@fpp.uni-lj.si
}

Received: 21 April 2020; Accepted: 9 May 2020; Published: 12 May 2020

\begin{abstract}
The berthing of an ultra large ship is always a difficult issue and becomes yet more complex when vessels must be handled in restricted manoeuvring areas of limited depth, exposed to a forceful crosswind, or manoeuvring in a strong current, or all three. The final approaching manoeuvre and precise positioning is particularly demanding at container terminals where many STS cranes are located along the quay, seriously limiting margin for error in the process of mooring a ship, especially when the cranes are located nearby a bridge wing or at the very edge of the pier. In order to avoid collisions, the final manoeuvre (side-push) must be fully controlled; the ship's orientation must be parallel with the quay while maintaining the minimum lateral approaching velocity without significantly shifting the vessel longitudinally. The mooring of a Ro-Ro vessel is occasionally even more challenging: a precise docking manoeuvre is normally executed without any towing assistance. In this paper low cost laser-based berthing and docking systems developed for the ports of Koper and Swinousce are presented and several berthing manoeuvres are analysed and compared with the most commonly used GNSS-based navigational aid system portable pilot units (PPU).
\end{abstract}

Keywords: container ship; precise positioning; portable pilot unit; gyro error; container terminal; berthing and docking; LiDAR scanner; STS crane

\section{Introduction}

Every port represents its own set of challenges to provide safe navigable waterways along with properly designed harbour approach channels [1]; adequate basin area available for manoeuvring and wharf approaching [2]; and guaranteeing completely safe berthing for particular ships for the duration of their stay [3]. Adverse weather can render even a well-designed mooring facility unsafe, but as long as the ship can safely leave the port or is carefully monitored while moored, such a port may still be considered safe. Ordinary good navigation and seamanship will not render a port unsafe [4]. This paper focuses on near shore vessel positioning required for safe berthing or docking, as well as monitoring vessels moored alongside. In berthing and unberthing situational awareness in the surrounding area is essential for the pilots and masters in order to take appropriate actions especially at the final manoeuvring stage where the speed of approach, distance, and angle of attack must be precisely determined. At the end, every vessel meets the berthing wharf, transferring a significant amount of energy, mostly depending on the ship's speed and its displacement tonnage [5]. It is obvious that the approaching speed must be controlled to avoid damaging the ship's hull, fenders, and other elements of berthing infrastructure.

According to the British Standard [6], risk reduction measures can consist of equipment installed on board the ship or at the berth. Such equipment could be either installed at shore with display units 
visible from the ship's bridge, or Portable Pilot Units (PPU) used on board the ship [7]. Various levels of awareness can be obtained from a PPU, which is currently used in many ports. It is a computer-based system that a pilot brings onboard a vessel to use as a decision-support tool for navigation, docking procedures or lock entry [8]. The unit is interfaced with either vessel positioning and heading sensors, or it may have its own advanced sensors providing centimetre position accuracy (less than $2 \mathrm{~cm}$ RMS when L1/L2 RTK GNSS service is available) and heading precision up to $0.01 \mathrm{deg}$. An advanced system is commonly used at LNG terminals and when other sensitive operations like the handling of very large vessels, narrow passages, side-by-side mooring and locking are involved in the process. PPU systems are definitely useful and highly recommended for pilots when handling vessels in the "ballistic" manoeuvring phase and during the final "side-pushing" or "positioning" phase when the elements of global satellite-aided positioning system (GNSS) are not obstructed and when the pilot has enough time to properly set-up the advanced PPU system; i.e., fill in receiving antenna positions (in body fixed coordinate system) and identifying the ships gyro heading offset, if possible.

At some locations, such as the port of Koper, the approaching and berthing pilotage phase is extremely short, so there often is not enough time to set-up an advanced PPU system (pilots sometimes execute more than 10 manoeuvres in their $12 \mathrm{~h}$ shift). Even so the GNSS satellite signal may be obstructed or redirected in certain navigational areas, thus consequently ordinary PPU based on ship's Automatic Identification System (AIS) does not always provide reliable data. Precise vessel position, transversal speed, and vessel-approaching angle are of great importance for safely berthing large container vessels particularly when inadequate fenders await and ship-to-shore (STS) cranes are near. The greatest pressure currently on ports is "Scale Enlargement," a euphemism for the incessantly increasing size of vessels along with the extreme pressure put on ports to accommodate this phenomenon. The rapid increase in ship sizes forces ports into a state of virtually constant adjustment. Container vessels are the best example of ships that grow faster than ports $[9,10]$. As early as 2004 an article warned of berthing challenges that would arise with ever bigger container ships; two particular challenges would be that they become more difficult to handle, and, worse, it would be difficult, at times impossible, to see the side of the quay once up close [11].

In recent years the cargo throughput in the port of Koper has averaged an annual growth of $8 \%$ with container growth as much as $16 \%$ yearly without an increase in the number of vessel calls. Management of this throughput was made possible by dredging activities and pier extension, allowing for the reception of larger vessels. Figure 1a depicts the evolution of the size of container ships calling at Koper in the last decade. The size doubles whether expressing deadweight tonnage (DWT) or Gross Tonnage (GT). When one of the larger vessels is alongside even minor yawing or list can cause contact with STS cranes, with catastrophic results. The extremely small gap between ship and crane is evident from Figure 1b.

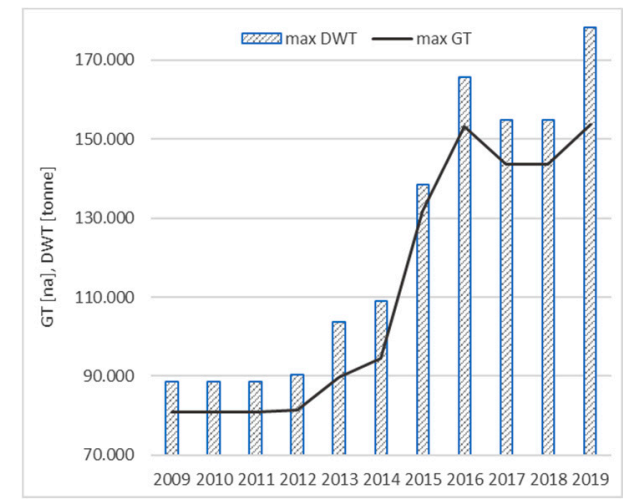

(a)

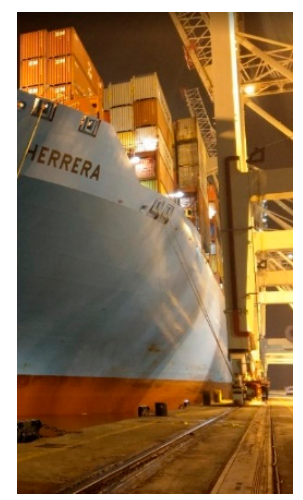

(b)

Figure 1. Evolution of the size of container ships calling at Koper (a) and ship-to-shore (STS) crane close proximity (b). 
The largest cranes, necessary for the largest vessels, must be fitted on the extant rails, which were designed, originally, to provide a safe distance between the vessels and cranes. This is not speculative, as one can see from the disastrous events of Figure 2 and Table 1, all occurring in 2019. Each of these collisions had a major impact on the port, aside from the already significant cost of replacing the damaged cranes. The port, at least near the incident, closes, the replacement can take up to a year, and of course operators may find an alternative port in the meantime.

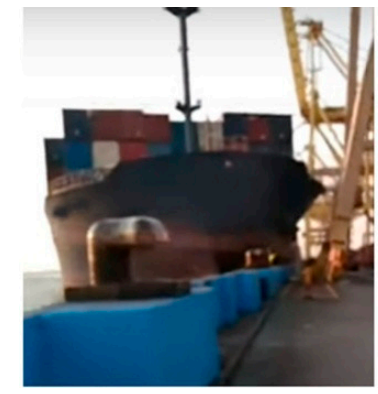

(a)

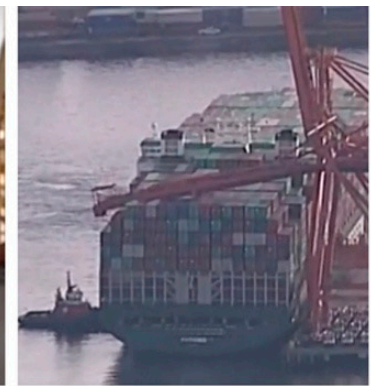

(b)

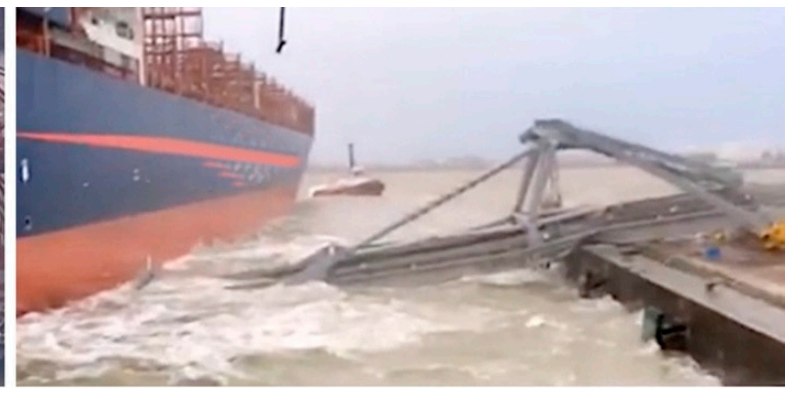

(c)

Figure 2. Container ship/crane collisions (a) with bow; (b) stern and (c) ships' bridge wing.

Table 1. Container ship/crane accidents in 2019.

\begin{tabular}{|c|c|c|}
\hline Date and Location & Vessel Name and Capacity/Size & Accident Description \\
\hline 2019/01/28, Vancouver, & $\begin{array}{l}\text { C/S “Ever Summit”, } 78612 \text { dwt, } \\
7024 \text { TEU, } 300 \times 42.9 \mathrm{~m}\end{array}$ & $\begin{array}{l}\text { Berthing: while a ship was pushed alongside } \\
\text { the dock the stern struck the crane located at } \\
\text { the edge of the terminal; the force of impact } \\
\text { knocked the crane rails off the quay, after which } \\
\text { the crane collapsed onto the ship. }\end{array}$ \\
\hline $\begin{array}{l}\text { 2019/02/03, Port of } \\
\text { Shuwaikh, Kuwait, }\end{array}$ & $\begin{array}{l}\text { C/S “Belgian Express”, } 25775 \\
\text { dwt, } 1794 \text { TEU, } 179.8 \times 27.6 \mathrm{~m}\end{array}$ & $\begin{array}{l}\text { Departure: while leaving the berth the vessel } \\
\text { collided with the gantry crane. }\end{array}$ \\
\hline $\begin{array}{l}\text { 2019/06/07, Hai Pong, } \\
\text { Container Terminal, } \\
\text { Vietnam }\end{array}$ & $\begin{array}{l}\text { C/S “Nagoya Express", } 103646 \\
\text { dwt, } 8749 \text { TEU, } 335 \times 42 \mathrm{~m}\end{array}$ & $\begin{array}{l}\text { Departure: while unmooring, the vessel } \\
\text { collided with a gantry crane that did not } \\
\text { collapse but was critically damaged. }\end{array}$ \\
\hline $\begin{array}{l}\text { 2019/07/14, Terminal } \\
\text { Petikemas Semarang in } \\
\text { Indonesia }\end{array}$ & $\begin{array}{l}\text { C/S “Soul of Luck" } 21519 \mathrm{dwt} \\
1642 \text { TEU, } 168.1 \times 27.2 \mathrm{~m}\end{array}$ & $\begin{array}{l}\text { Berthing: a feeder vessel approached at a high } \\
\text { angle and hit the gantry crane with its bow - the } \\
\text { crane collapsed. }\end{array}$ \\
\hline $\begin{array}{l}\text { 2019/12/09, Antwerp, } \\
\text { DP World Terminal }\end{array}$ & $\begin{array}{l}\text { C/S “APL Mexico City”, } 115024 \\
\text { dwt, } 9326 \text { TEU, } 328.2 \times 45.2 \mathrm{~m}\end{array}$ & $\begin{array}{l}\text { Mooring breakaway: vessel drifted as her } \\
\text { mooring broke due to strong wind, } \\
\text { unsuccessful towing assistance, vessel's bridge } \\
\text { wing hit the STS crane (unmanned), which } \\
\text { collapsed and destroyed the quay. }\end{array}$ \\
\hline
\end{tabular}

During the last decade, the development of ship sizes of Ro-Ro/Ro-Pax vessels and the scale enlargement of product tankers have also been problematic. As the vessel sizes and amount of traffics increases, safe and efficient berthing becomes more challenging worldwide. Among the many incidents in recent years, in the port of Koper in 2017 a Ro-Ro vessel, having moored then broken away, crashed into the bulk terminal, knocking over a crane, seriously damaging the pier (100 meters had to be replaced).

The worst of this type of accident occurred just as this paper was being finalized (on 6 April 2020 in Busan port). Due to an uncontrollable high-speed, the container ship "Milano Bridge" collided with an entire strip of container cranes on the dock. Only one of the six gantry cranes remained functional after the accident. As possible causes, the investigators cited not only speed, but also a shorter reaction time after turning, insufficient power from tugs due to the high forward speed and lack of effect of the bow thrusters. The crew had not taken into account the fact that the ship was empty and was sailing 
with a partially submerged rudder, nor had they sufficiently considered the local weather conditions and, on top of all that, the pilot panicked as the ship approached the dock. Given the extraordinary cost of the cranes, the economic impact requires no elaboration.

\section{Berthing Aid System, Development and Some Applications}

\subsection{An Historic Overview}

The need for berthing support systems first emerged in the oil and gas industry. With increasing size and complexity of tankers, the owners had to pay more attention to potential risk factors when planning to handle larger ships, preventing possible damage to both jetties and ships, and, of course, preventing environmental pollution (along with insurance and demurrage). In the early 1970s the first mooring load monitoring system was developed in Norway, based on strain-gauged load measuring pins installed into the quick release hooks to measure the tension in the mooring line [12]. The first real docking and monitoring system integrated with sonar-based speed of approach measurement, environmental and meteorological sensors, was designed in 1990 [12]. At almost the same time developments in the measurement of speed of approach were tending to favour radar-based applications-ultrasonic systems had a problem with surrounding water and fouling of the ships' hull. The radar also had some difficulties [11], not being a focused sensing device, backscattering data must be filtered and any changes in surroundings like a moved or moving crane would require additional filtering, a software upgrade. Finally, with the development of eye-safe lasers more accurate and reliable berthing and docking measurements in all weather conditions were made possible. Comparison of ultrasound, radar and laser diode ranging systems using a dedicated scale is presented in Table 2, considering: range, power, dependability of weather, beam size, method of measurement, refresh rate, price and lifetime. Ultrasound can be eliminated, and both radar and laser ranging solutions are capable of being used in berthing and docking systems. A laser-based ranging system is not subject to weather; the most significant problem theoretically is reflectivity of the measured object (the vessel in this case). With radar a microwave is reflected by the flat surfaces and the method of measurement used here-frequency modulated continuous wave (FMCW)-provides a very reliable solution with the same antenna for received and transmitted signals. The pulse system used in the lasers is resistant to external interferences and usually is coded. The FMCW method used in radars is very rugged and not affected by interference. Because of the range factor, radar is not used to their full potential; lasers have better flexibility. Another consideration is that radar is approximately 5 times more expensive than laser.

Table 2. Comparison of methods.

\begin{tabular}{cccc}
\hline \multirow{2}{*}{ Parameter } & \multicolumn{3}{c}{ Ranging Method } \\
\cline { 2 - 4 } & Laser Diode & Radar & Ultrasounds \\
\hline Range & to $300 \mathrm{~m}$ & to $2 \mathrm{~km}$ & to $10 \mathrm{~m}$ \\
Emission power & $10 \mathrm{~mW}($ laser $)$ & $10 \mathrm{~mW}(96 \mathrm{GHz})$ & $1 \mathrm{~W}$ (sound $)$ \\
Beam & Very narrow $(<2 \mathrm{deg})$ & Narrow $(<5 \mathrm{deg})$ & Wide $(>5 \mathrm{deg})$ \\
Weather dependability & Low & Very Low & Significant \\
Price & Average & Very High & Low \\
Method of measurement & FMCW & Pulse & Continuous-interrupted \\
Refresh rate & $0.1 \mathrm{kHz}$ & $1 \mathrm{kHz}$ & $0.001 \mathrm{kHz}$ \\
Lifetime & Average & Average & High \\
\hline
\end{tabular}

Another advancement is the integration of the ranging system with others, like positioning, environmental, and PPU. Among others a non-commercial alternative has been provided by a laser measurement system integrated with a high precision positioning pilot navigation docking system (PNDS), which was proposed for the docking of LNG vessels [13]. A low-cost integrated laser ranging and berthing system integrated with meteorological and oceanographical data (MetOcean) 
was developed for the safe passage through the narrow winding channel and the final berthing of large vessels calling at the container terminal in the port of Koper [14] (the precise descriptions apply to the methods used at the port of Koper; others may, for instance, place the LiDARs in different strategic locations). Installing ranging devices on moving STS cranes is more complicated compared to jetty installation, where sensors are at fixed positions. When a container vessel is berthing, STS cranes are tied down to the wharf structure (wharf anchorage) at s known position, so the exact LiDAR positions are always known. LiDARs and processing units are located on the STS (ship to shore) crane, just above the wheels or about at $2 \mathrm{~m}$ height (Figure 3). For the sake of accuracy, while the vessel is approaching, the STS crane (one with LDS units) shall be located wherever the vessel's outline is parallel. The parallel body of the vessel hull can be found at the middle part and can be as much as $60 \%$ of the vessel length. The equipment used for measurements is a combination of different sensors and modules that are remotely controlled by pilots through specific user interfaces.

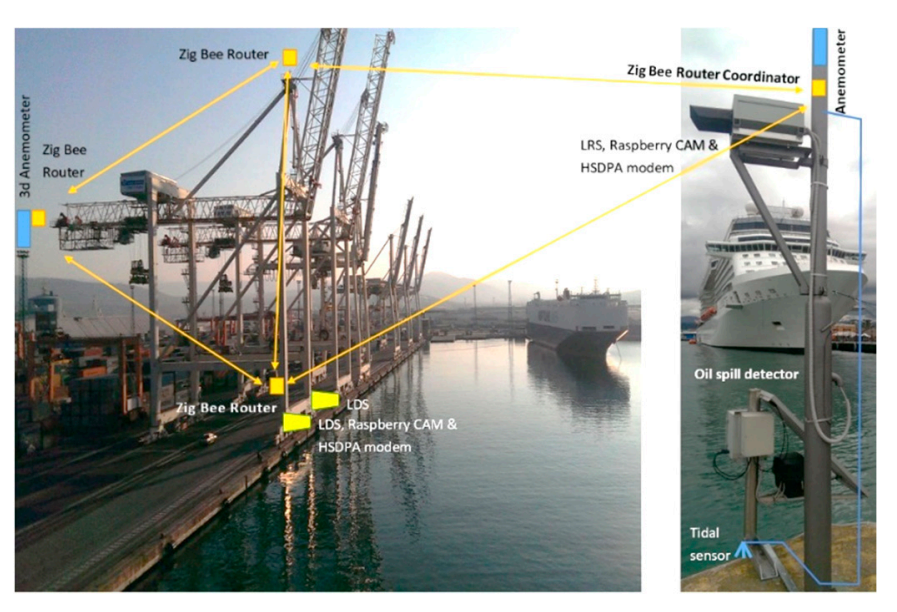

(a)

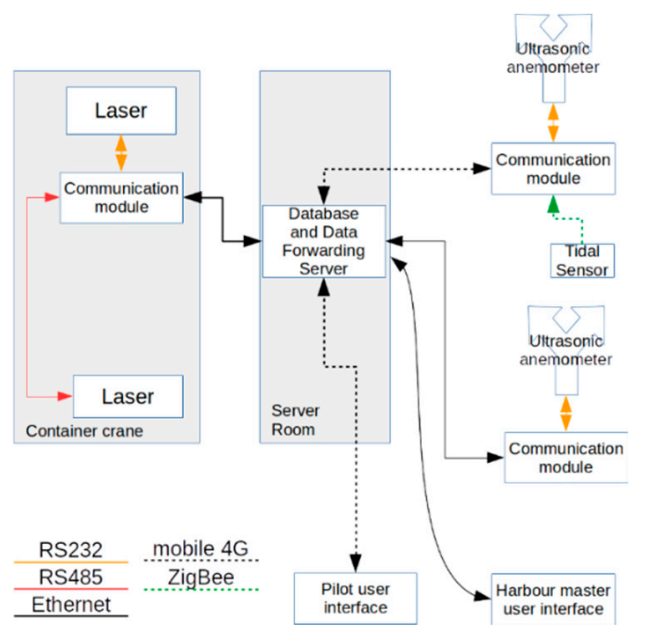

(b)

Figure 3. Laser ranging and berthing system (a) port of Koper installation, (b) communication protocol.

The list of equipment is shown in Table 3. In order to extend laser diode lifetimes, devices are powered on demand. The laser distance meters in the docking system provide $2 \mathrm{~cm}$ accuracy for distances up to $300 \mathrm{~m}$, while the ranging sensor provides $1.5 \mathrm{~cm}$ accuracy up to $400 \mathrm{~m}$. All anemometers are able to measure wind velocities in three directions between 0 and $65 \mathrm{~m} / \mathrm{s}$, which is sufficient in the area of interest. Measurement can be provided at a sample rate of $20 \mathrm{~Hz}$. The resolution of the ultrasonic tidal sensor is $1 \mathrm{~cm}$.

Table 3. Comparison of methods.

\begin{tabular}{ccc}
\hline Device & Model & Application \\
\hline Laser Distance Meter (diode based) & Riegl LD90 & Ranging sensor \\
Laser Distance Meter (diode based) & Jenoptik LDM301 & Docking system \\
ZigBee to SIO module & Digi XBEE-PRO XBP24 & For remote tidal sensor data transm. \\
Utrasonic Distance Meter & MaxBotix XL-MaxSonar WR1 & For tide measurement \\
Ultrasonic 3D anemometer & Gill WindMaster PRO & Wind velocity measurement \\
Ultrasonic 2D anemometer & Gill WindObserver 65 & Wind velocity measurement \\
\hline
\end{tabular}

\subsection{Some Applications}

The berthing aid or docking system measures the precise distance from which lateral speed and orientation of an approaching vessel is calculated in real time. Even though this system can monitor vessel movement only when it is allied with the jetty (i.e., when both laser beams are reflected from the parallel part of vessel hull called parallel body), it still provides invaluable information to the 
captain or pilot when berthing a ship. Additionally, such a system can be used as a vessel drift warning system, identifying uncontrolled vessel movements caused by passing vessels that cause ship-to-ship interaction, or when a ship is moved by strong winds or currents. Furthermore, the entire docking operation is thus recorded, and the data can be used to evaluate potential incidents.

In order to measure the longitudinal position of an approaching vessel, the laser system must be integrated with the vessel's AIS system, providing GNSS data and the ships' heading information. When precise front-end docking is required (Ro-Ro), a differential GNSS system which provides centimetre accuracy can be used along with 3D laser scanning devices.

Data gained from the berthing aid system are additionally applied for the development of new port design recommendations and standards; i.e., researchers have been investigating different methods of fender design. Sakakibara and Kubo [15] used a docking sonar system and found actual berthing conditions that were not in line with those used for design purposes. They have presented a measurement of pressure on pneumatic fenders; Metzger et al. [16] conducted a similar study based on using ultrasonic distance sensors calculating vessel kinematics and analysing pressure on fenders. Yamse et al. [17] analysed more than 2500 instances of berthing velocities in various conditions (14 terminals in 6 countries) and found that their results did not fit the Brolsma curve [18] used as a standard for designing fenders based on vessel velocity, displacement tonnage, and navigational conditions. One of the most important discoveries [17] is that winds blowing under $10 \mathrm{~m} / \mathrm{s}$ do not contribute to the increase in berthing velocity. At winds under $10 \mathrm{~m} / \mathrm{s}$ the berthing velocity depends solely on the ship and its port assistance. They found that there is no need to divide ports and berthing velocities into five groups; Rather they have grouped berthing velocities in types A and B, based on operator experience and environmental conditions (Table 4). Ueda [19] statistically analysed laser-based measured berthing velocities-obtained at different container terminals located in Japan and elsewhere in East Asia. Large vessel berthing impact was analysed by Hein [20] where vessel kinematics was measured with radar-based systems, while Roubus et al. [21] and Kirbiš et al. [22] used a laser-based system. Berthing velocities are relatively low in the port of Koper, as fairly indicated in the study. Berthing velocities are significantly lower even for group A, where excellent operators are handling vessels in temperate MetOcean conditions.

Table 4. Berthing velocities.

\begin{tabular}{|c|c|c|c|c|c|}
\hline \multirow{3}{*}{\multicolumn{2}{|c|}{ Berthing Velocity }} & \multirow{2}{*}{\multicolumn{2}{|c|}{$\begin{array}{l}\text { Port of Koper Study [22] } \\
\text { Large Container Ships }\end{array}$}} & \multicolumn{2}{|c|}{ Various Ports [17] } \\
\hline & & & & Group A & Group B \\
\hline & & \multirow{2}{*}{$\begin{array}{c}\begin{array}{c}\text { Angle of Attack } \\
\text { (deg) }\end{array} \\
0.48\end{array}$} & \multirow{2}{*}{$\begin{array}{c}\begin{array}{c}\text { Berthing Velocity } \\
\text { (cm/s) }\end{array} \\
3.05\end{array}$} & \multicolumn{2}{|c|}{$\begin{array}{l}\text { Berthing Velocity } \\
(\mathrm{cm} / \mathrm{s})\end{array}$} \\
\hline & Average & & & $3.9-5.4$ & $6.7-9.3$ \\
\hline $95 \%(2 \delta)$ & Confidence value & 1.74 & 7.21 & $7.7-11.3$ & $14.1-16.9$ \\
\hline $99 \%(3 \delta)$ & Confidence value & 2.26 & 8.96 & $9.4-16.0$ & $19.3-23.8$ \\
\hline
\end{tabular}

In the scope of unmanned navigation, which is still solving a variety of technical problems, largely to do with automation [23], the laser ranging and berthing system is one of the core subsystems of autonomous surface vessels required for collision avoidance [24,25].

\section{Performance: Comparison Between the Pilot Navigation System and LiDAR}

\subsection{System Structures and Measurements}

Pilot navigation systems are sometimes seen as alternatives to the pier-mounted laser and radar systems. Suppliers claim superior accuracy in terms of positioning, heading and rate of turn (ROT) measurements. The systems, however, mostly rely on non-RTK capable GNSS receivers that are vulnerable to disturbances of satellite signals. It was assumed that even under normal conditions, the reliability of such systems could be compromised in some cases, especially if the geometry of the 
structures in the area is such that it could cause multipath signal travel. Therefore, a comparison of different systems' performances for berthing applications was carried out. In order to carry out such a comparison, AIS logs from the pilot navigation systems and from ships were decoded using special purpose Python scripts in conjunction with Libais library. The event timestamps are from the pilot navigation systems that have time synchronization through the GNSS. For laser measurements, NTP time synchronization on logging computers was used in order to obtain correct measurement time.

When the ship's fixed GNSS position data was analysed, AIVDO/AIVDM designated messages were used; And when the pilot navigation system was used as a positioning source, the supplemental GPGGA message was used to obtain positions and custom HEHDT and HEROT vendor specific messages were used for heading and rate of turn.

All measurements were resampled and aligned for comparison using the Pandas Python processing library. In Figure $4 \mathrm{a}$ an overview of measurement equipment positions is shown. Several LIDARs were evaluated, from high frequency low end model (HS) with $\pm 50 \mathrm{~mm}$ accuracy to higher precision crane-mounted (JEL, JER) $\pm 20 \mathrm{~mm}$ accuracy, and also high-precision (HP) with $\pm 1 \mathrm{~mm}$ accuracy that was used as a reference to compare all other sensors. Two Jenoptik LDS301 units were mounted on a crane at a fixed distance and used to determine the orientation relative to the quay and fenders. During the testing, an additional LiDAR was used (Riegel), (parameters in Table 5). Distance $d$ was measured, unknown variable in the test case. In order to compare the accuracy of pilot navigation systems with LIDARs, it was necessary to calculate the position of the ship's edge from the AIS and GNSS data. AIS and GNSS positions are in the form of geographical latitude and longitude converted into a local coordinate system that converted positions into distance units (meters). The ship's GNSS position is shown as the point $P_{g}\left(x_{g}, y_{g}\right)$. The vector $\vec{O}_{s}$ is a unit vector representing ship orientation and is calculated from the heading data.

$$
\overrightarrow{O_{s}}=\left(\cos \left(\pi / 2-\psi_{g}\right), \sin \left(\pi / 2-\psi_{g}\right)\right)
$$

Vector, perpendicular to the ship orientation is

$$
\overrightarrow{O_{p}}=\left(\cos \left(-\psi_{g}\right), \sin \left(-\psi_{g}\right)\right)
$$

They are used to obtain points $P_{1}$ and $P_{2}$ on the ship's edge facing the pier

$$
\overrightarrow{P_{1}}=\overrightarrow{P g}+h \overrightarrow{O_{p}}
$$

and $P_{2}$ a translation of s meters along $\vec{O}_{s}$ direction is calculated

$$
\overrightarrow{P_{2}}=\overrightarrow{P_{1}}+s \overrightarrow{O_{s}}
$$

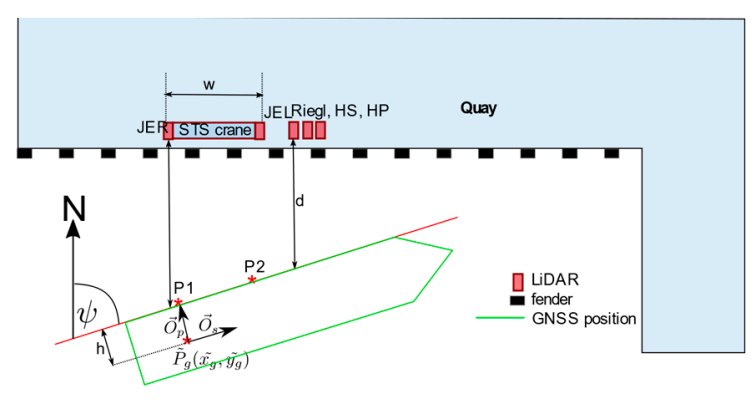

(a)

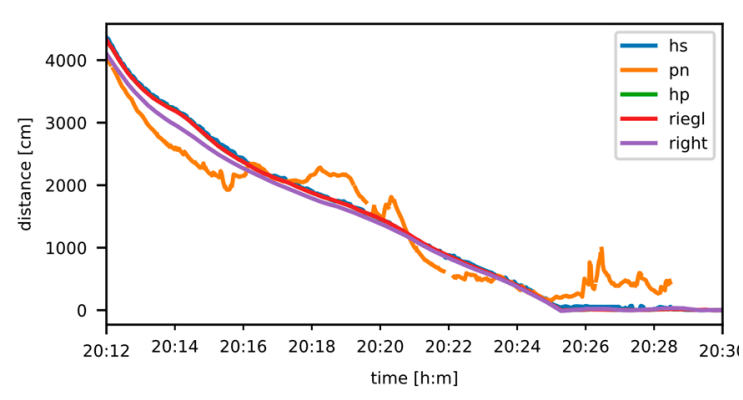

(b)

Figure 4. Measurement equipment setup and ship data (a), measured distance $d$ versus time (b). 
Table 5. LIDAR parameters.

\begin{tabular}{|c|c|c|c|c|c|}
\hline Laser Rangefinder Model & Abbr. & $\begin{array}{c}\text { Range } \\
\text { (m) }\end{array}$ & $\begin{array}{l}\text { Accuracy } \\
(\mathrm{mm})\end{array}$ & $\begin{array}{l}\text { Sampling Frequency } \\
\text { (Output) (Hz) }\end{array}$ & $\begin{array}{c}\text { Wavelength } \\
(\mathrm{nm})\end{array}$ \\
\hline Riegl LD90 & Riegl & $\begin{array}{c}150 \\
1000 *\end{array}$ & \pm 15 & 1 & 905 \\
\hline Jenoptik LDM301 & $\begin{array}{l}\text { JEL } \\
\text { JER }\end{array}$ & $\begin{array}{c}300 \\
3000 *\end{array}$ & \pm 20 & 100 & 905 \\
\hline Foresight FST-B200 & HS & 200 & \pm 50 & 200 & 905 \\
\hline Foresight FST-100M & $\mathrm{HP}$ & 100 & \pm 1 & 10 & 635 \\
\hline
\end{tabular}

Once the points $P_{1}(x 1, y 1)$ and $P_{2}(x 2, y 2)$ are obtained, equations for the line defining the ship's edge are obtained. The distance $d$ is obtained by calculating the distance between the obtained line and the LiDAR positions perpendicular to the pier.

In Figure 5a, it can be seen that as the vessel is tugged closer to the pier that measured distances between different sensors are minimized. However, the pilot navigation system data is apparently showing unrealistic changes in positions due to suspected multipath problems, at least from positions recorded in the log. The errors when the vessel position was supposed to be constant (after 20:26) were about 5 meters. However, a comparison between the pilot navigation system and ship's own GNSS receiver reveals that the ship's receiver performs significantly worse, which is shown in Figure 5a.

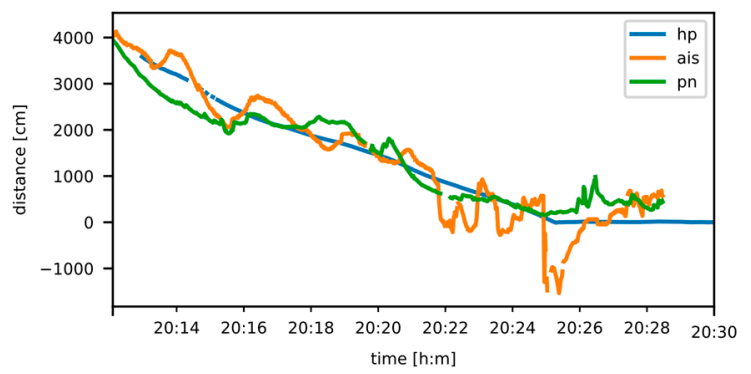

(a)

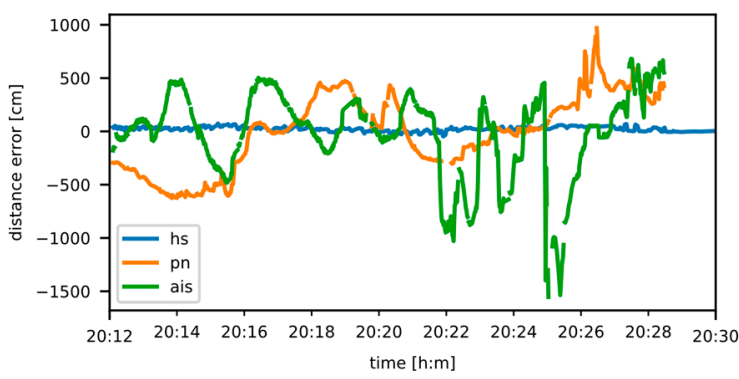

(b)

Figure 5. Comparison of LIDAR reference, ship and pilot navigation system (a) and distance errors of ship GPS, pilot navigation system and worst LIDAR (b).

To determine errors shown in Figure 5b, the differences between the range obtained from ship GNSS, pilot navigation system, the worst and best LiDAR as references are shown. Even the worst, low-cost LiDAR is orders of magnitude more precise than common pilot navigation systems, especially in the areas affected by the multipath disturbances. However, with the pilot navigation system, position error was mostly within $5 \mathrm{~m}$ while the ship GNSS yielded far worse results, even though it has antennas placed at much more favourable locations than portable pilot systems. In order to illustrate the quantification of the measurement results presented in Figure 5, Root Mean Square Error (RMSE) and maximum absolute errors recorded are shown in Table 6. The results indicate significant errors in the GNSS-based systems in the vicinity of the overhead cranes and the strong benefit of using even low-end LIDAR (relative errors calculated at $5 \mathrm{~m}$ ). The results suggest that it would be beneficial to augment the GNSS data using local LiDAR measurements in order to obtain more accurate position during the docking procedures. 
Table 6. Comparison of positioning errors.

\begin{tabular}{ccccc}
\hline Sensor & RMSE (cm) & Max Error $(\mathbf{c m})$ & Mean Relative Error (\%) & Max Relative Error (\%) \\
\hline HS LiDAR & 28 & 73 & 2 & 14 \\
\hline Pilot Navigation & 355 & 969 & 25 & 189 \\
\hline AIS & 406 & 1553 & 31 & 307 \\
\hline
\end{tabular}

\subsection{Fusion of AIS, PPU and LiDAR Measurements}

Fusion of the AIS position data and local measurements taken with LiDARs or radars mounted in the dock would be beneficial for pilots during docking procedures. This way LiDAR precision and reliability would be combined with AIS data, which provides longitudinal positioning along the pier (Figure 6). The calculation is done using the UTM coordinate system. Location of lasers onshore is given by points $\left(x_{01}, y_{01}\right)$ and $\left(x_{02}, y_{02}\right)$. Coordinates of the vessel's port side parallel body are given by

$$
x_{i}=x_{0 i}+d_{i} \sin \alpha, y_{i}=y_{0 i}-d_{i} \cos \alpha, i=1,2
$$

where $d_{i}$ is offset of the LiDARs and the angle a represents the orientation of the pier

$$
\alpha=\arctan \frac{y_{02}-y_{01}}{x_{02}-x_{01}}
$$

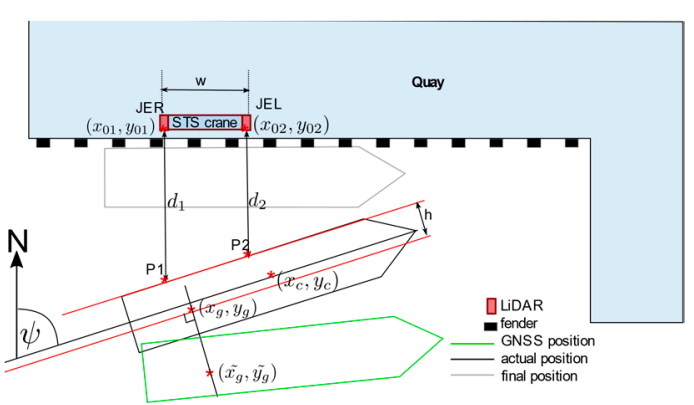

(a)

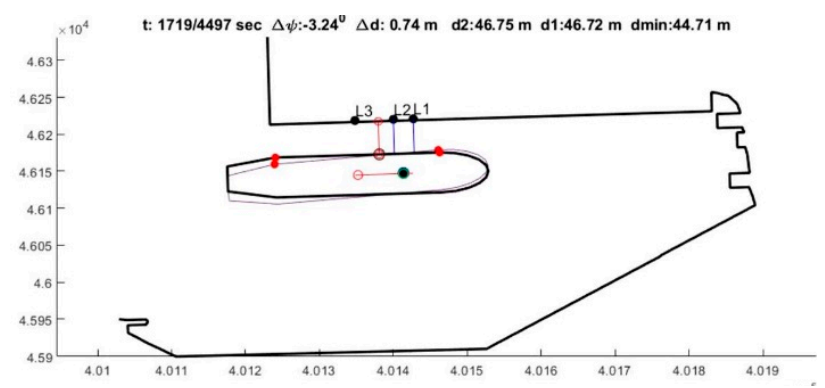

(b)

Figure 6. Fusion of GNSS and LiDAR measurements, model (a), final positioning (b).

Coordinates of the GNSS antenna on the ship, which is where AIS position data is obtained from, are $\left(x_{a}, h_{a}\right)$ in the ship's relative coordinate system, which is the right side coordinate system with its origin in ship's centre, where $x$ axis is directed from stern to bow. The location of the AIS transmitter from the left side parallel body is

$$
h=\frac{B}{2}+h_{a}
$$

Approximate GNSS coordinates transmitted by the ship over the AIS are $\left(\widetilde{x_{g}}, \widetilde{y_{g}}\right)$ and heading is $\widetilde{\psi_{g}}$. The obtained approximate ship coordinates will be used in the following calculation. The equation defining the starboard side parallel body edge of the vessel is

$$
y=k x+n
$$

where coefficient $k$ and intersection $n$ are calculated from points determined by the LiDAR measurements.

$$
k=\frac{y_{2}-y_{1}}{x_{2}-y_{1}} \text { and } n=y_{1}-k x_{1} .
$$


The precise GNSS antenna line is obtained from LiDAR-measured ship edge Equation (8) by translating a distance $h$ towards the centre, obtaining the line

$$
y=k x+n-h \sqrt{1+k^{2}}
$$

Since precise GNSS antenna line is obtained from LiDAR measurements, longitudinal position of the vessel must be determined from the AIS data by projecting the GNSS coordinates $\left(x_{g}, y_{g}\right)$ on the line specified by the Equation (10), obtaining

$$
\begin{gathered}
x_{g}=\frac{\widetilde{x_{g}}+k\left(\widetilde{y_{g}}-n+h \sqrt{1+k^{2}}\right)}{1+k^{2}} \text { and } \\
y_{g}=\frac{k \widetilde{x_{g}}+n+k^{2} \widetilde{y_{g}}-h \sqrt{1+k^{2}}}{1+k^{2}} .
\end{gathered}
$$

This way we obtain the projected coordinates on the line specified by quay-mounted LIDARs, where $x_{g}$ and $y_{g}$ are relative coordinates from a reference point on the quay. They are calculated from approximate values of the corresponding coordinates obtained from the GNSS receiver $\widetilde{x_{g}}$ and $\widetilde{y_{g}}$. The $k$ and $n$ are the projection line coefficient and intersection and $h$ is the offset of the ship GNSS antenna position from the side edge. The process is illustrated in the Figure 6. The ship heading is obtained by

$$
\psi=\frac{\pi}{2}-\arctan (k)
$$

The centre of the ship is therefore at the following point

$$
\begin{aligned}
& x_{c}=x_{g}-x_{a} \cos \psi+h_{a} \sin \psi, \\
& y_{c}=y_{g}-x_{a} \sin \psi-h_{a} \cos \psi .
\end{aligned}
$$

This way the ship's position and orientation are obtained by merging the accurate LiDAR measurements of ship to pier distances and longitudinal position from GNSS obtained AIS data.

Figure $6 \mathrm{~b}$ depicts the real interface of data fusion. The actual berthing of Maersk Herrera: The bold line is the outline of the vessel measured by lasers; The thin line is that obtained by the PPU. The PPU takes the position from the ship's GNNS while the orientation of the ship is additionally filtered by the PPU (parameters in Table 7). As the data suggests, the position of the ship is quite good, but the orientation is insufficiently prepared for berthing. Extensive analysis of berthing led us to discover that aside from multipath disturbances, the greatest problem is the tendency for gyro error to be greater than the maximum IMO standards of what should be accepted. The orientation is attributable to gyro error; and for a ship that size, such an orientation error could mean a deviation of up to ten meters from where the pilot and captain think the bow of the vessel is.

Table 7. Automatic Identification System (AIS) and global satellite-aided positioning system (GNSS) receiver features.

\begin{tabular}{cccc}
\hline GNSS Data Source & Abbr. & Position/Orientation Accuracy & Type \\
\hline Ship's GNSS & AIS & variable & depending on the vessel age and type \\
\hline SafePilot CAT ROT & PN & 0.1 deg heading & pilot navigation system \\
\hline SafePilot CAT I & PN1 & $0.7 \mathrm{~m}$ RMS & pilot navigation system \\
\hline
\end{tabular}

\subsection{PPU: Limitation of the GNSS and Ship's GYRO}

Marine pilots in the Port of Koper have observed sudden jumps of the vessel or tug in certain areas, on their monitoring equipment. The effect may well be related to the presence at least of two types of reflective objects in the surroundings: port cranes and the surface of the sea [26]. In order to apply the variance model, a strong correlation must exist between the satellite elevation angle and 
the GNSS signal quality. But variance models become inefficient when observations are affected by multipath, signal diffraction and receiver characteristics. For measurements collected under non-ideal observational conditions, direct signal quality measures such as signal-to-noise ratio (SNR) based variance models can be more appropriate for assessing the quality of GNSS observations. Furthermore, pseudorange multipath error mitigation methods exist (e.g., [27]), but they are not yet widely applied in the commercial maritime fleet.

The behaviour of the navigation solution and consequently its accuracy is subjected to a combination of diffuse forward scattering and fluctuations of very low frequency [28]. Secondary path signals with longer propagation time distort the amplitude and phase of the direct-path signals. As a consequence, the code ranges are more susceptible to multipath than carrier phases. Since the signals received from lower-elevated satellites are more prone to multipath (elevation-dependent weighting concept), observing the elevations of the satellites in view may contribute to a realistic model. But modelling of the propagation situation, e.g., [29] (p. 156), in the case of the port of Koper is based on navigational solution reports from vessels' AIS data. The crucial knowledge regarding which satellites were actually included in the determination of navigational solutions when anomalous behaviour occurs is missing. In the absence of signal quality monitoring, but assuming that no interfering in-band signals were affecting the navigation solution, a decision was made that spatial distribution of anomalous changes of navigational solutions would be mapped from the reports, and not from the GNSS satellite-receiver tracks.

A collection of AIS Class A messages, contains data: time, latitude, longitude, heading, Rate of Turn, Course over Ground, Speed over Ground. Data were preliminarily analysed without flags for the differential correction status (corrected, uncorrected), Position Accuracy (high $<=$, low $>10 \mathrm{~m}$ ) and RAIM (in use, not in use).

The following figure, Figure $7 \mathrm{a}, \mathrm{b}$ present the reported positions of two vessels. Green dots represent positions with speed corresponding to SOG, while blue lines represent anomalous events of rate of position exceeding SOG by more than twice.

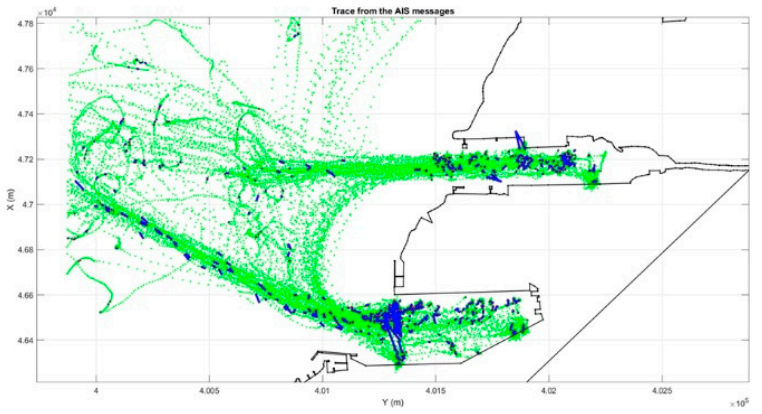

(a)

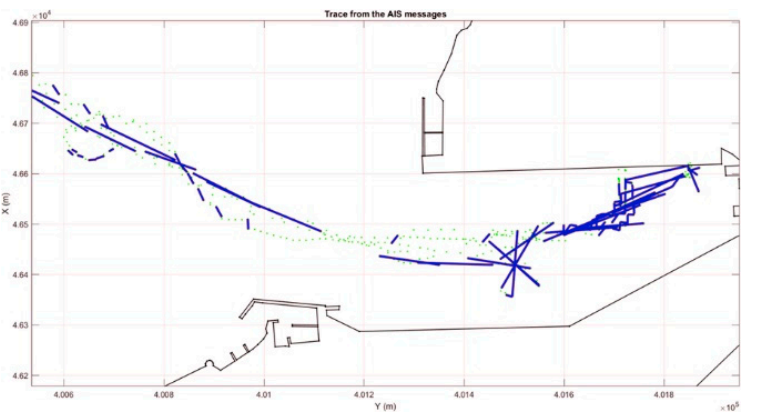

(b)

Figure 7. Anomalous parts of the tug's Zeus track (a) and container ship Murat K track (b) as observed in AIS messages from September 1-24 2019, Port of Koper, coordinate system D96 (UTM).

The gyrocompass is an indispensable navigational instrument which should determine the direction of the ship's heading in relation to geographic (true) north. Various systems on board ship are under the control of the Master Gyro; the gyrocompass system transmits information to the Steering Console, RADAR, ECDIS, AIS, GNSS, VDR, GMDSS equipment, and other equipment or systems as required, such as PPU. The accuracy of predicted position can be significantly affected upon the occurrence of gyrocompass errors, especially during berthing manoeuvres. According to performance standards IMO A.424(XI), gyro error should not exceed $0.75 \times$ secant latitude and the root mean square value of the differences between individual heading indications, and the mean should be less than $0.25^{\circ} \times$ secant latitude. Gyro settling error can be estimated from the orientation of a moored ship alongside a quay. A long-term study involving the collection of AIS data from the container terminal, 
where larger ships are assumed to be constantly moored parallel with the quay, provided 56 berthing events at berth 7 at port of Koper for our evaluation. The average observed absolute gyrocompass error equalled $1.4^{\circ}$, with a standard deviation of $1.1^{\circ}$, significantly higher than IMO standards. There is no reason to believe that this is not generally the case involving the gyrocompass.

\section{Advanced Integrated LiDAR Based Docking System Specifically for Ro-Pax}

\subsection{Layout}

To extend the capabilities of a positioning system based on laser distance measurements, an extended system based on laser scanners has been proposed. A test version of such a system has been implemented at a terminal ferry in the port of Świnoujście, Poland. It consists of two 3D LiDAR sensors located in such a way that bow/stern and the sides of the ship can be scanned at any time during the berthing/unberthing manoeuvre. LiDARs specification is given in Table 8 and the full architecture of the system is presented in Figure 8 and consists of laser scanners, two CCTV cameras, server, AIS receiver, anemometer, power system and data network.

Table 8. LiDARs specification (outdoor use).

\begin{tabular}{cc}
\hline Laser Class & 1 (IEC 60825-1:2014, EN 60825-1:2014) \\
\hline Aperture angle & $\begin{array}{c}\text { Horizontal } 85^{\circ} \text { (working range with } 4 \text { measuring planes, } 5^{\circ} \text { extension } \\
\text { of working range with } 2 \text { measuring planes to a total of } 110^{\circ} \text { ), vertical } 3.2^{\circ}\end{array}$ \\
\hline Scanning frequency & $12.5 \mathrm{~Hz} \ldots 50 \mathrm{~Hz}$ \\
\hline Angular resolution & $0.125^{\circ}, 0.25^{\circ}, 0.5^{\circ}$ \\
\hline Working range & $0.5 \mathrm{~m} \ldots 300 \mathrm{~m}$ \\
\hline Scanning range at 10\% remission & $50 \mathrm{~m}$ \\
\hline Amount of evaluated echoes & 3 \\
\hline Detectable object shape & Almost any \\
\hline Systematic error & $\pm 300 \mathrm{~mm}$ \\
\hline Statistical error & $100 \mathrm{~mm}$ \\
\hline Integrated application & Field evaluation \\
\hline Number of field sets & 16 fields \\
\hline Simultaneous evaluation cases & 16 \\
\hline Ambient operating temperature & $-40{ }^{\circ} \mathrm{C}+70{ }^{\circ} \mathrm{C}$ \\
\hline
\end{tabular}

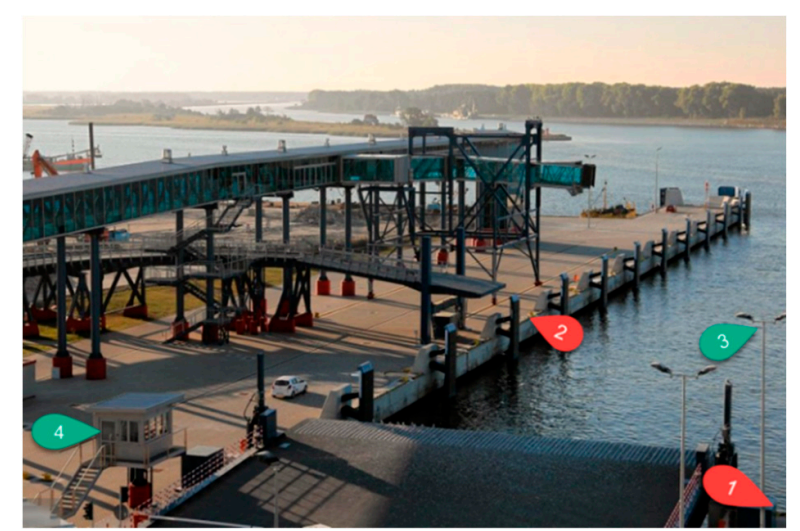

(a)

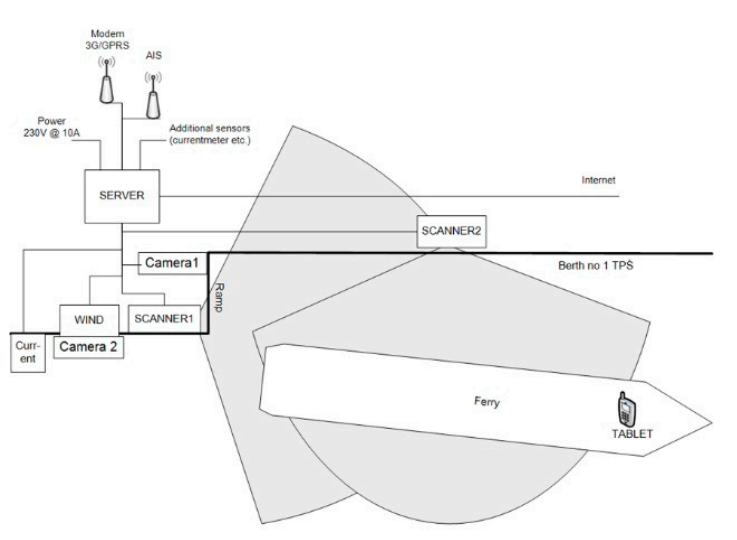

(b)

Figure 8. Ferry post no 1 in Świnoujście port and the location of the system devices: 1,2-laser scanners, 3-anemometer and camera, 4-camera, AIS receiver, server (a), photo taken by C.Aszkiełowicz. System diagram (b). 
The data from the system are provided by on-board tablets which communicate with a server hosted application via LTE internet connection. Such an approach makes it simple to update and extend the application remotely, without the need to access the end users' devices. The application provides information about the ship's outline in relation to the berth, together with minimum distances: ship's side, berth and ship's bow/stern ramp. It also provides wind data, calculated velocities (longitudinal and transversals) and calculated heading.

\subsection{Positioning, Velocity Determination and Ship Orientation Algorithm}

Since it is impossible to establish the exact geometry of the hull and the actual draft of a ship using only two LiDARs, the system has been adapted for two specific ferries that use the berth on a daily basis. For each ship a family of outline shapes has been prepared, taking into consideration expected changes in draft. The positioning algorithm, after reading data points from both LiDARs, performs the following operations (Figure 9a):

1) Removes points identified as berth points (based on ( $x, y)$ coordinates)

2) Removes isolated points, i.e., points that do not have any neighbouring points in a $5 \mathrm{~m}$ radius

3) Approximates ship's side-line using the RANSAC algorithm

4) Removes outliers

5) Estimates ship's side using the Least Square Method (LMS)

6) Removes false points, e.g., points from seagulls flying low, inside the scanner's range

7) Finds the best estimation for ship's stern/bow

8) Returns best fit of ship's position.

The position of the ship's stern/bow is estimated by minimizing the sum of squares of distances between points and the ship's outline. This operation is repeated no less than 100 times (until the result does not improve by more than 0.00001 ). In Figure 10, the ship's sideline is illustrated, along with the points that were used to determine it. The points that are detected by the individual LiDAR are drawn in corresponding colours, in red and blue.

The RANSAC algorithm is used specifically to estimate the best line that fits points acquired by both LiDARs by minimizing a monotonically increasing function of the absolute values of the signed error for each point:

$$
e_{M}(d ; \Theta)=\frac{\Theta_{1} x_{1}+\Theta_{2} x_{2}+\Theta_{3}}{\sqrt{\Theta_{1}^{2}+\Theta_{2}^{2}}}
$$

The exact implementation of the RANSAC algorithm, based on [30], performs the following steps:

1) Selects two points randomly.

2) Solves in regard to the line parameters.

3) Determines how many points from the set of all points fit with a tolerance of $0.15 \mathrm{~m}$.

4) If less than 70 percent of all points exceeds the assumed tolerance, repeats steps $1-3$ but not more than 1000 times.

5) Otherwise, terminate the algorithm.

After the RANSAC algorithm is terminated a set of points located not more than $0.2 / 0.5 \mathrm{~m}$ (depending on the given ship) is selected. This set is used to re-estimate the line using the Least Square Method. The ship's state obtained from RANSAC is base position and course vector $\left(x_{i}, y_{i}, K_{i}\right)$; it is transformed in every time step into velocities $\left(v_{x}, v_{y}, \omega\right)$. In this case the filtering and tracking itself is performed by algorithm based on a very simple and robust exponential smoothing by Holt method with Pegels' multiplicative trend and additional damping (Figure 9b) [31]. The applied algorithm allows the estimation of the location of the ship's gravity centre and course in the next time step $\left(x_{i+1}\right.$, $\left.y_{i+1}, K_{i+1}\right)$, the ship's velocities in 3 degrees of freedom $\left(v_{x}, v_{y}, \omega\right)$, and the future (predicted) ship 
parameters given up to $3 \mathrm{~min}$ (ship tendency). The smoothing is done in separate steps for all three parameters $\left(v_{x}, v_{y}, \omega\right)$ according to the following formula:

$$
\begin{gathered}
X_{t}(m)=S_{t} R_{t}^{\varphi} \\
S_{t}=\propto X_{t}+(1-\propto)\left(S_{t-1} R_{t-1}^{\varphi}\right) \\
R_{t}=\gamma\left(\frac{S_{t}}{S_{t-1}}\right)+(1-\gamma) R_{t-1}^{\varphi}
\end{gathered}
$$

where:

$\alpha, \gamma$-smoothing coefficient,

$\phi$-dampening coefficient,

$X_{t}(m)$ —estimated parameter.

The values of smoothing coefficients $(\alpha, \gamma, \phi)$ have been estimated based on the real time simulation trials for Ro-Pax ferries where minimum values of mean square errors were found for all estimated values.

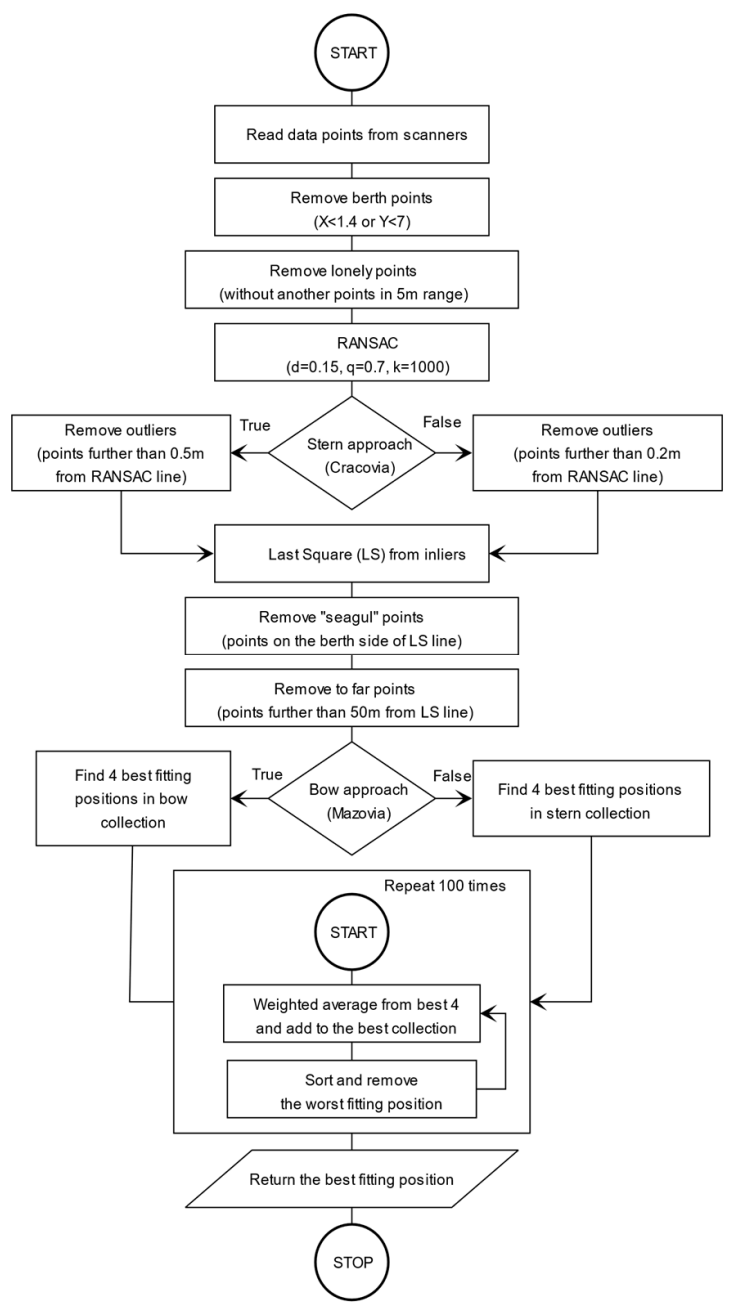

(a)
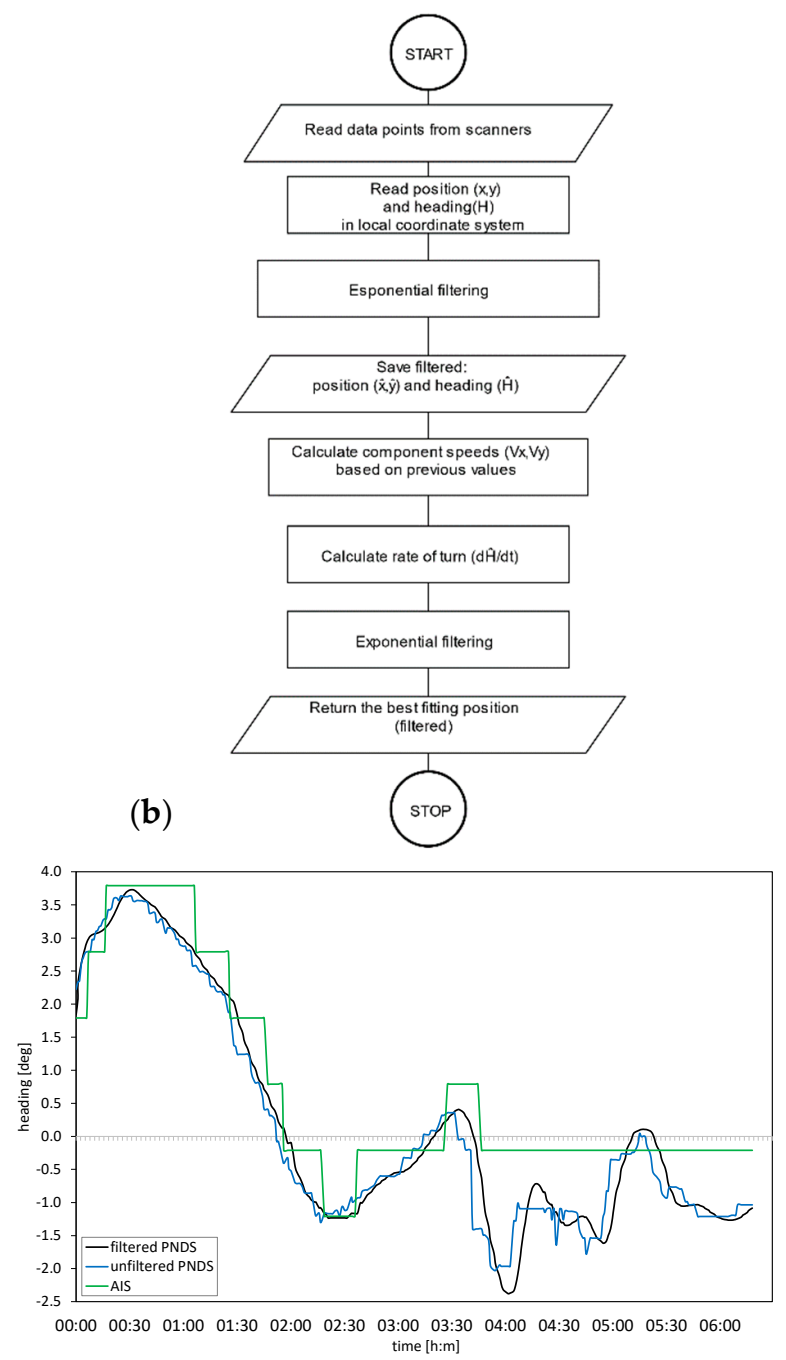

(c)

Figure 9. Algorithm for ship's position estimation (a); estimation and smoothing algorithm for course and velocities (b) with processed ship's true heading (c). 


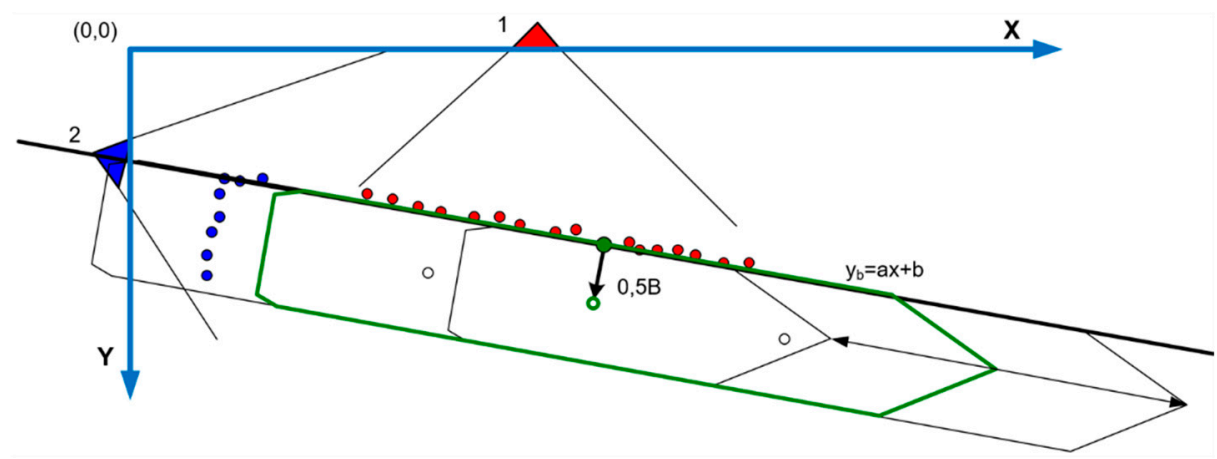

Figure 10. Estimation of ship's position from LIDARs measurements.

\subsection{Verification of the System's Performance}

During the stage of system development, the verification of system performance and algorithm accuracy was based on the comparison between the position calculated by the system and the position reported by the AIS system. A system of cameras was utilized as well to visually evaluate the stages of the manoeuvre and ship's dynamics. All comparisons were made using the developer version of the application. The first stage of the verification was based on a comparison between the position reported by the AIS system (GNSS position) and the position calculated by the PNDS algorithm. Due to the number of AIS messages, equal to around 6 messages per minute, only positions at the time of a new message were compared.

The point for which the AIS position is reported was evaluated statistically by measuring and analysing the position of the ferry when it was moored. For both ships it was evaluated as the point located on the longitudinal symmetry axis, $153 \mathrm{~m}$ from the aft perpendiculars for the Cracovia ferry and $140 \mathrm{~m}$ from the aft perpendicular for the Mazovia ferry. The observed position deviation for the estimated AIS points is equal to $0.82 \pm 0.40 \mathrm{~m}$. An example of values reported by the AIS and calculated by PNDS system are shown by Figure 11 (Ais R-heading, in relation to the north, Scan Rheading in relation to the berth; check both green and blue frames). Taking into consideration the lack of detailed information about the location of CCRP on both ships, delays during transmission, and the reception of AIS messages and the general accuracy of the GNSS system, the observed position accuracy may be acknowledged as very high and in accordance with PNDS system assumptions.

\subsection{Verification of the System Under Real Conditions}

The PNDS system was installed on two ferries. In both cases a tablet docking station was installed in accordance with the recommendations and requirements of the captains. Each captain was fully informed about the functionality and restrictions of the system and was trained to use it. Two developers took part in a first voyage after the installation to check the performance of the system and answer any question the captains might have. Because of differences in cargo operations the ferries approach their berth in different ways.

The Mazovia ferry moves to the southern part of the berth, enters the turning circle located next to the Basen Bałtycki, rotates and approaches the berth moving north, parallel to the berth. The general average approach is shown in Figure 12a. The Cracovia ferry reduces velocity to $0-1$ knot and using thrusters approaches parallel to the berth. At the last stage, the ship corrects location along the berth (Figure 12b).

Longitudinal speed, lateral speed, and angular speed are calculated directly form changes of position and rotation of the ship's outline in time. The application of kinematic equations and an exponential filter gives the basis for an assumption that the accuracy of speed indication directly depends on how often and how accurate the system calculates course and position. Independently from the above assumption, a set of comparisons during manoeuvres was conducted. 


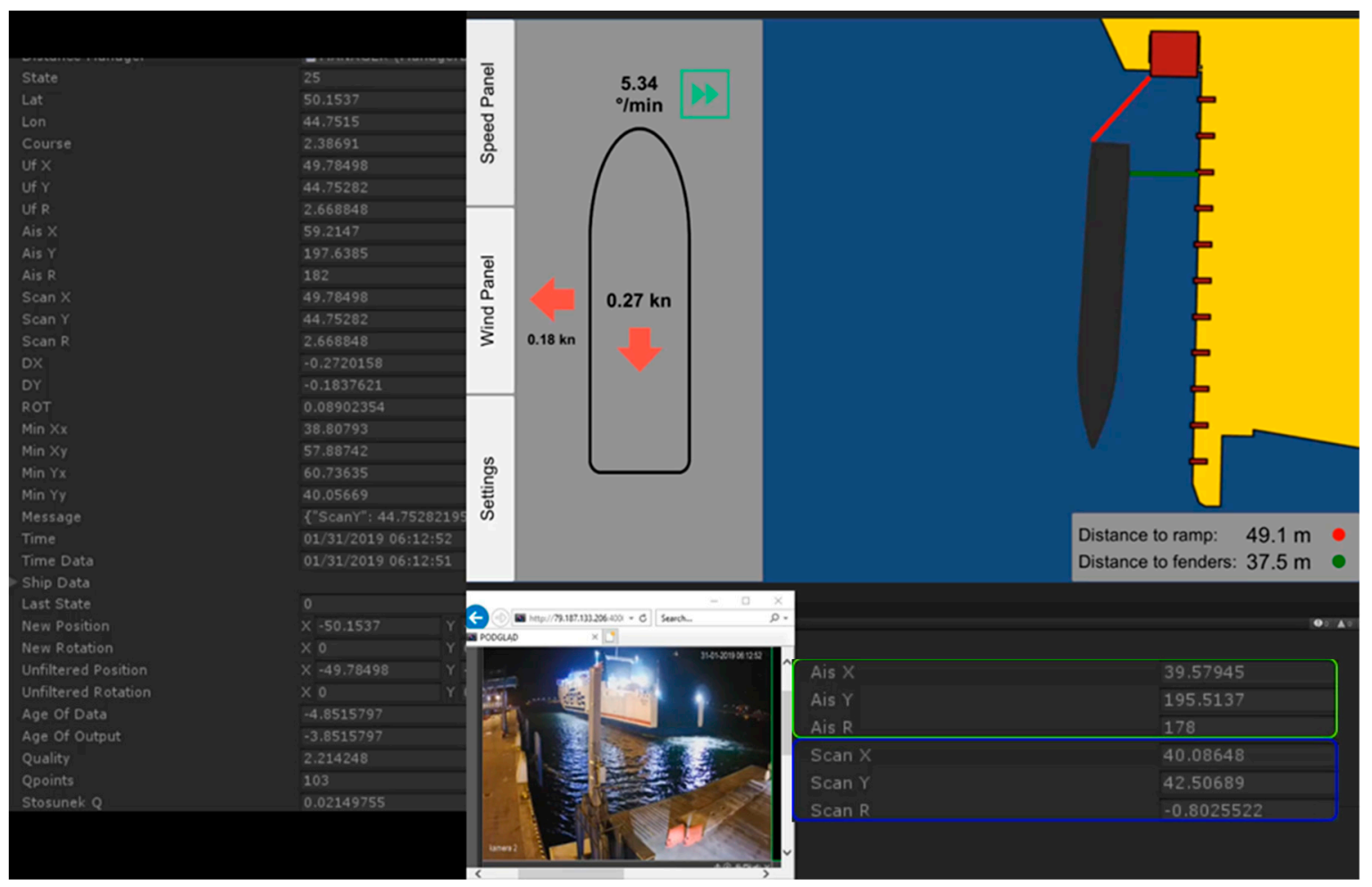

Figure 11. Test application prepared for the purpose of verification of pilot navigation docking system (PNDS) system and comparison of position reported AIS and calculated by PNDS system (green and blue frames).

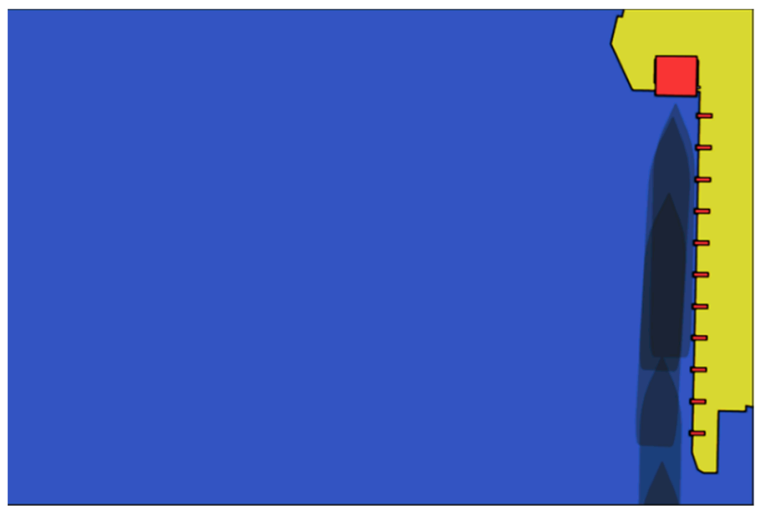

(a)

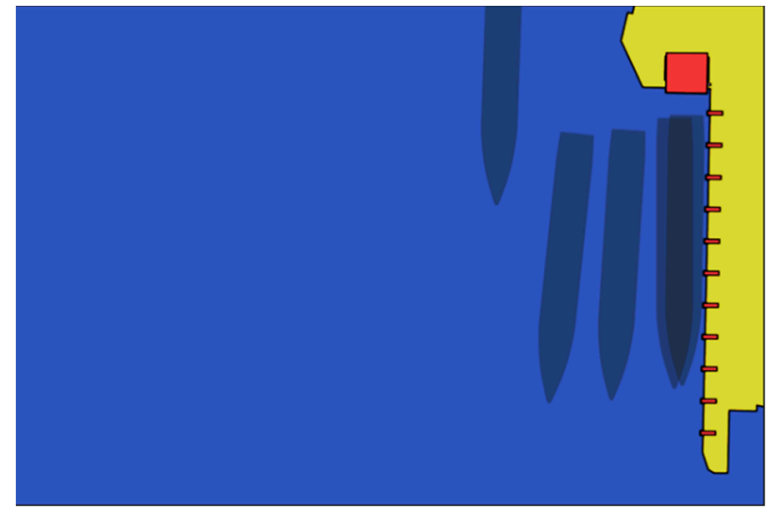

(b)

Figure 12. Mazovia ferry longitudinal approach (a), Cracovia ferry in transversal approach (b).

All comparisons included recording speed values from on board equipment (like log and gyrocompass) and values from the PNDS system. Because the PNDS system can calculate the speed only when the ship is in range of both laser scanners, the time when the comparison could be made was only a few minutes during each manoeuvre. In $72 \%$ of randomly chosen moments linear velocities shown by on-board equipment did not differ by a more than $15 \%$. In the case of angular speed, the average difference was \pm 1.5 degree/min. It was noted during those test that the on board equipment that is used during manoeuvres displays longitudinal and lateral speeds with an accuracy of 0.1 knots (Figure 13a), while the PNDS systems displays those values with an accuracy of 0.01 knots (Figure 13b). Thus, the PNDS system provides more accurate data. 


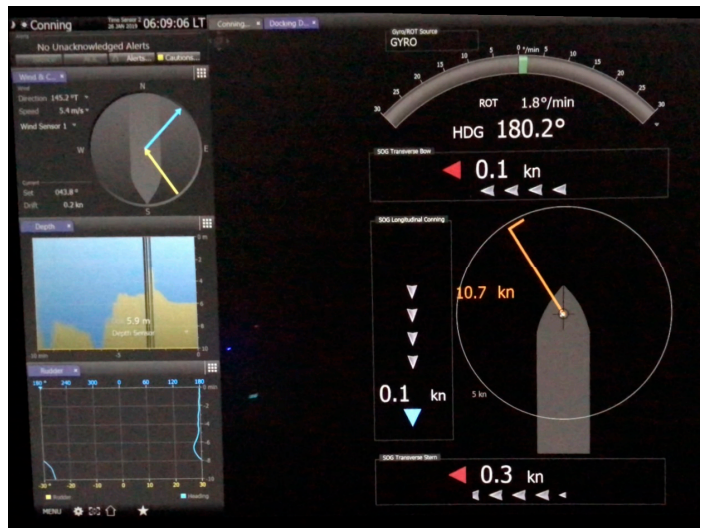

(a)

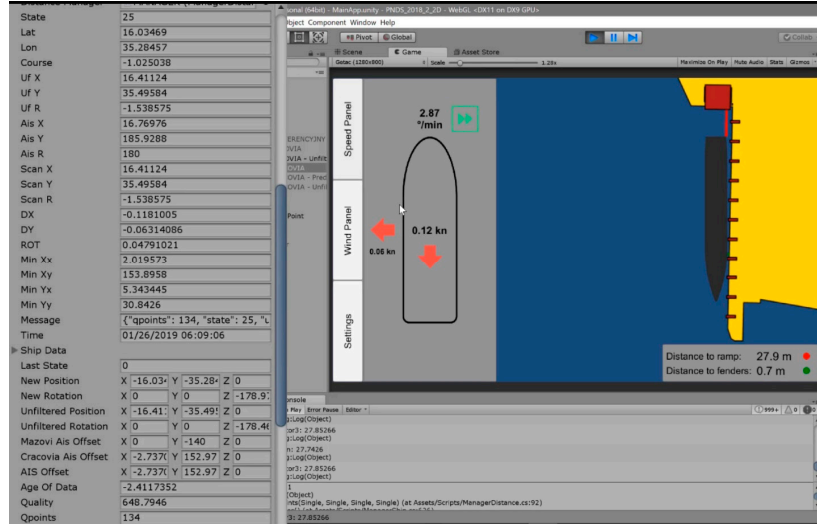

(b)

Figure 13. Comparison of speed and tendency of the Cracovia ferry during berth approaching: data available through ship's conning station (a), and PNDS (b).

Values of distances calculated by the system were verified with the use of a standard, handheld laser distance meter when the ships were moored. Due to the opened bow door on the Mazovia ferry it was not possible to measure an exact distance between the ramp and the ship's outline (Figure 14a). For the Cracovia ferry the calculated distance from the ramp to the stern differed by a margin of $15 \mathrm{~cm}$ when compared to manual measurements. Such a difference is acceptable as per system assumptions. Figure 14b,c shows ship's side measurements.

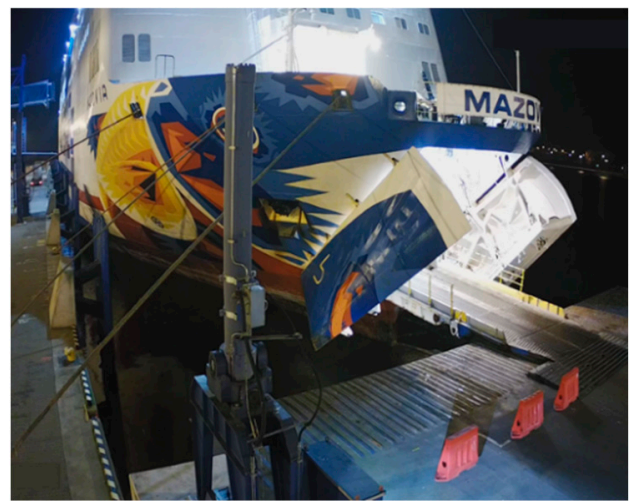

(a)

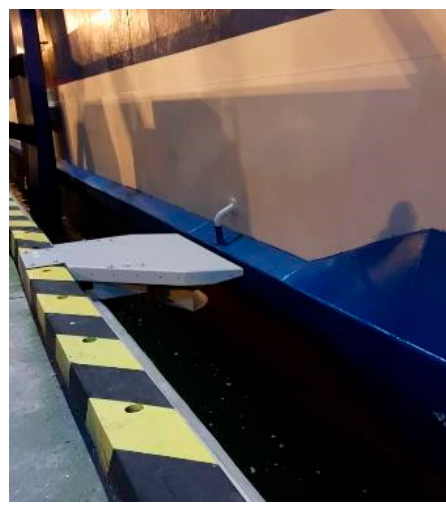

(b)

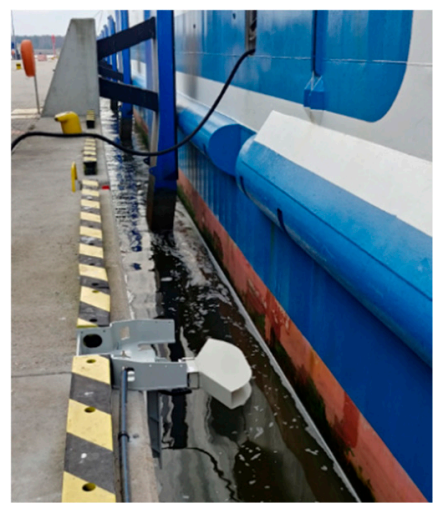

(c)

Figure 14. Location of the $\mathrm{m} / \mathrm{f}$ Mazovia bow in relation to the ramp during cargo operations on Ferry post no 1 (a). Location of the $\mathrm{m} / \mathrm{f}$ Mazovia side in relation to the berth. Laser scanner, shore fender and ship's bumper are visible. The system reports correct distance between the ship and fenders (b). Location of the $\mathrm{m} / \mathrm{f}$ Cracovia side in relations to the berth. Laser scanner, shore fender and ship's bumper are visible. The system reports incorrect distance between the ship and fenders (c).

Regarding the distance between the berth and sides of the ferries, the maximum observed difference was over 90 centimetres. Two main factors responsible for such a difference were identified:

(1) Documentation of both ferries does not represent the accurate shape of the external hull-just the general layout and the shape of a theoretical outline at deck levels. This data was used to create hypothetical ship outlines that are used for the system during calculations.

(2) On both ferries the external hull has an extruded bumper throughout its length. This bumper is the point of direct contact between the ship and the fender. Without the information about current ship's draft and the shape of the external hull it is not possible to evaluate whether the laser scanner measures the distance to the side of ship or to the bumper. 
This can lead to a situation where the ship is in contact with the fender, but the laser scanner measures the distance to the ship's side, so the system reports the distance of around $0.5 \mathrm{~m}$. Because of this, the system does not report exact distances between 0 and $0.5 \mathrm{~m}$ Instead it shows that the distance is less than $0.5 \mathrm{~m}$.

\section{Conclusions}

Experts in maritime commerce rightly lament the dangerous speed of growth of vessels, particularly in the container business. However, in one instance a great deal of expense and an increasing threat has been solved at an extremely low cost. The laser-based berthing and docking system is the safest means of ensuring the integrity of the berthing and docking process (the system installed at the port of Koper has been operating without failure or degradation for five years at the moment of this writing). PPU is perhaps good enough when obstructions like cranes do not exist, but where they do, their accuracy is not sufficiently reliable. Where PPU appears good enough, a laser-based system is an inexpensive means of even safer berthing and if nothing else should be made available for purposes of redundancy. A novel way of fusing GNSS positioning data with LIDAR measurements has been proposed. The benefit of such a system is the combination of ship GNSS longitudinal position with its lesser accuracy with the high-precision lateral positioning, thus minimizing the risk of collision.

The loss of a crane, which we have been using as our worst case scenario, is catastrophic for a port even without death and injury - the expense is immense, and the time to repair the area of a fallen crane and the replacement of it is considerable. There have been numerous ship-to-crane collisions resulting in damage measured in millions of Euros, and a lidar-based system is significantly less than 1 percent of likely damage in the case of a single accident. The only limitation in regard to the system is the impossibility of spreading the lasers far enough apart at, for instance, container terminals to be absolutely certain of the orientation of the ship to the quay.

For the needs of Ro-Ros, which require the most precise docking, an advanced integrated docking system was developed based on 3D scanners combined with the PPU system, finally providing a working solution to the problem of the need for clear outlines of vessels both laterally and longitudinally as they approach the pier.

Author Contributions: Conceptualization, M.P., L.G.; methodology, L.G., M.P., B.L.; data collection: B.L., M.P., L.G., V.L.; software, M.B. (Milan Batista), B.L., B.M., M.B. (Mateusz Bilewski); validation, M.P., B.L., P.V., F.D. All authors have read and agreed to the published version of the manuscript.

Funding: This research received no external funding.

Acknowledgments: The authors acknowledge the Port of Koper, the Slovenian Maritime Administration, marine pilot Matjaž Felicjan, and Blaž Kirbiš.

Conflicts of Interest: The authors declare no conflict of interest.

\section{List of Acronyms}

AIS

AIVDO/AIVDM

$\mathrm{C} / \mathrm{S}$

CCRP

CCTV

DWT

ECDIS

FMCW

GMDSS

GNSS

GT

HEHDT/HEROT

IMO
Automatic Identification System

NMEA AIS sentence format, where; AI-Mobile AIS station; VDO-AIS VHF Data-link

Own-vessel report; VDM-AIS VHF Data-link Message

Container Ship

Consistent Common Reference Point

Closed-Circuit Television Camera

Deadweight Tonnage

Electronic Chart Display and Information System

Frequency Modulated Continuous Wave

Global Maritime Distress and Safety System

Global Navigation Satellite System

Gross Tonnage

Vendor specific messages where; HDT-True Heading Data; ROT-Rate of Turn

International Maritime Organization 


$\begin{array}{ll}\text { LDS } & \text { Laser Docking Sensor or System } \\ \text { LiDAR } & \text { Light Detection and Ranging } \\ \text { LMS } & \text { Least Square Method } \\ \text { LNG } & \text { Liquefied Natural Gas } \\ \text { LTE } & \text { Long-Term Evolution } \\ \text { MetOcean } & \text { Meteorology and Oceanography } \\ \text { NMEA } & \text { National Marine Electronics Association; tandard for data interchange in marine } \\ \text { NTP } & \text { navigation systems } \\ \text { PNDS } & \text { Network Time Protocol } \\ \text { PPU/PN } & \text { Pilot Navigation and Docking System } \\ \text { RADAR } & \text { Portable Pilot Unit/Pilot Navigation Sistem } \\ \text { RAIM } & \text { Radio Detecting And Ranging } \\ \text { RANSAC } & \text { Receiver autonomous integrity monitoring } \\ \text { Ro-Pax } & \text { Random sample consensus } \\ \text { Ro-Ro } & \text { Roll-On-Roll-Off-Passenger-ship/ferry } \\ \text { ROT } & \text { Roll-On/Roll-Off } \\ \text { RTK } & \text { Rete of Turn } \\ \text { SNR } & \text { Real-Time Kinematic } \\ \text { SOG } & \text { Signal-to-Noise Ratio } \\ \text { STS } & \text { Speed Over Ground } \\ \text { TEU } & \text { Ship to Shore } \\ \text { UTM } & \text { Twenty-Foot Equivalent Units } \\ \text { VDR } & \text { Universal Transverse Mercator } \\ & \text { Voyage Data Recorder }\end{array}$

\section{References}

1. PIANC. Harbour ApproacH Channels Design Guidelines, PIANC Report $n$ 121; The World association for Waterborne Transport infrastructure: Brussles, Belgium, 2014.

2. ROM 3.1-99. Recommendations for Maritime Works, Design of the Maritime Configuration of Ports, Approach Channels and Harbour Basins; Puertos del Estado: Madrid, Spain, 2007.

3. Kharchanka, A. The Meaning of a Good Safe Port and Berth in a Modern Shipping World. Ph.D. Thesis, University of Groningen, Groningen, The Netherlands, 2014. Available online: https://www.rug.nl/research/ portal/files/32037387/Complete_thesis.pdf (accessed on 7 January 2020).

4. Rabeaux, J. Safe Ports and Berths in a Nutshell, Defence Guides DCG-SPB-GBR-19-V1, West of England Insurance Services. 2016. Available online: https://www.westpandi.com/getattachment/bda5d2f7-8283-43e1abbb-9727e7c7a0cb/safe_ports_and_berths_4pp_v2_lr.pdf (accessed on 20 April 2020).

5. Carbonari, S.; Gara, F.; Antolloni, G.; Gara, F.; Lorenzoni, C.; Mancinelli, A. A performance-based approach for the design of coupled dolphin-fender berthing structures. Marine Struct. 2019, 64, 78-91. [CrossRef]

6. BS 6349-4:2014. Maritime Works_Part 4: Code of Practice for Design of Fendering and Mooring Systems; BSI Standards Limited: London, UK, 2014.

7. Selwyn, P. Better docking for both pilots and terminals. J. Ports Termin. 2015, 66, 1-2.

8. APA. Portable Pilots' Units: A Best Practices Summary, American Pilots' Association. 2016. Available online: http://www.americanpilots.org/PPUBestPracticesAPA_\%2027Oct2016.pdf (accessed on 7 January 2020).

9. Perkovic, M.; Brcko, T.; Luin, B.; Vidmar, P. Ship Handling Challenges When Vessels are Outgrowing Ports. In Proceedings of the IMLA-INSLC 19 Proceedings, South African Maritime Training Academy, Western Cape, South Africa, 5-7 September 2016.

10. Merk, O. Container Ship Size and Port Relocation, Discussion Paper; International Transport Forum: Paris, France, 2018.

11. Integrating the Laser-Docking Made Easier with Advanced Systems Engineering. Available online: https://www.motorship.com/news101/industry-news/integrating-the-laser-docking-made-easierwith-advanced-systems-engineering (accessed on 20 April 2020).

12. Thomas, S. An integrated approach to vessel berthing. J. Ports Termin. 2012, 27, 1-2. 
13. Gucma, L.; Bak, A.; Jankowski, S.; Zalewski, P.; Perkovic, M. Laser docking system integrated with Pilot Navigation Support System, background to high precision, fast and reliable vessel docking. In Proceedings of the 17th Saint Petersburg International Conference on Integrated Navigation Systems, St. Petersburg, Russia, 31 May-2 June 2010.

14. Perkovic, M.; Gucma, M.; Luin, B.; Gucma, L.; Brcko, T. Accommodating larger container vessels using an integrated laser system for approach and berthing. Micropocess Microsist 2017, 52, 106-116. [CrossRef]

15. Sakakibara, S.; Kubo, M. Ship berthing and mooring monitoring system by pneumatic-type fenders. Ocean Eng. 2007, 34, 1174-1181. [CrossRef]

16. Metzger, A.T.; Hutchinson, J.; Kwiatkowski, J. Measurement of marine vessel berthing parameters. Mar. Struct. 2014, 39, 350-372. [CrossRef]

17. Yamse, S.; Ueda, S.; Okada, T.; Arai, A.; Shimizu, K. Chracteristics of Measured Berthing Velocity and the Application for Fender Design of Berthing Ship. In Proceedings of the 33rd PIANC World Congress, San Francisco, CA, USA, 1-5 June 2014.

18. Rankine, B. Berthing Velocities and Brolsma's Curves. Project Report; Marine Consulting Engineers: London, UK, 2010.

19. Ueda, S. Observation of Berthing Velocity (Japan and East Asia) and Statistical Analysis (Overall ports). In Proceedings of the 33rd PIANC World Congress, San Francisco, CA, USA, 1-5 June 2014.

20. Hein, C. Berthing velocity of large container ships. In Proceedings of the 33rd PIANC World Congress, San Francisco, CA, USA, 1-5 June 2014.

21. Roubos, A.; Groenewegen, L.; Peters, D.J. Berthing velocity of large seagoing vessels in the port of Rotterdam. Mar. Struct. 2017, 51, 202-219. [CrossRef]

22. Kirbiš, B.; Perkovič, M.; Luin, B. Port of Koper Fighting the Growth of the Ships and Trying to Accommodate Large Container Vessels Using Laser-Ranging System. Available online: https://www.researchgate.net/publication/327816531_Port_of_Koper_Fighting_The_Growth_of_ Ships_and_Trying_to_Accommodate_Large_Container_Vessels_Using_a_Laser-Ranging_System (accessed on 11 May 2020).

23. Autonomous Shipping Concepts. 2020. Available online: https://www.norclub.no/blog/autonomousshipping-concepts/ (accessed on 7 January 2020).

24. Van Cappelle, L.E.; Chen, L.; Negenborn, R.R. Survey on Short-Term Technology Developments and Readiness Levels for Autonomous Shipping. In Computational Logistics; Cerulli, R., Raiconi, A., Voß, S., Eds.; Springer: Berlin/Heidelberg, Germany, 2018.

25. Spange, J. Autonomous Docking for Marine Vessels Using a Lidar and Proximity Sensors. Ph.D. Thesis, Norwegian University of Science and Technology, Trondheim, Norway, 2016.

26. Rumora, I.; Sikirica, N.; Filjar, R. An Experimental Identification of Multipath Effect in GPS Positioning Error. TransNav Int. J. Mar. Navig. Saf. Sea Transp. 2018, 12, 29-32. [CrossRef]

27. Pirsiavash, A.; Broumandan, A.; Lachapelle, G.; O’Keefe, K. GNSS Code Multipath Mitigation by Cascading Measurement Monitoring Techniques. Sensors 2018, 18, 32. [CrossRef] [PubMed]

28. Mekik, Ç. An investigation on multipath errors in real time kinematic GPS method. Sci. Res. Essays 2010, 5, 2186-2200.

29. Hofmann-Wellenhof, B.; Lichtenegger, H.; Wasle, E. GNSS_Global Navigation Satellite System; Springer: Berlin/Heidelberg, Germany, 2008.

30. Zhang, X.; Xu, W.; Dong, C.; Dolan, J.M. Efficient L-shape fitting for vehicle detection using laser scanners. In Proceedings of the IEEE Intelligent Vehicles Symposium (IV), Los Angeles, CA, USA, 11-14 June 2017.

31. Taylor, J.W. Exponential Smoothing with a Damped Multiplicative Trend. Int. J. Forecast. 2003, 19, 715-725. [CrossRef]

(C) 2020 by the authors. Licensee MDPI, Basel, Switzerland. This article is an open access article distributed under the terms and conditions of the Creative Commons Attribution (CC BY) license (http://creativecommons.org/licenses/by/4.0/). 